\title{
High-resolution Manometry in Patients with Gastroesophageal Reflux Disease Before and After Fundoplication
}

\author{
Katarzyna Rerych, ${ }^{1}$ Józef Kurek, ${ }^{2}$ Ewa Klimacka-Nawrot, ${ }^{1}$ Barbara Błońska-Fajfrowska, ${ }^{1}$ and Antoni Stadnicki ${ }^{1,3 *}$ \\ ${ }^{I}$ Department of Basic Biomedical Sciences, School of Pharmacy with the Division of Laboratory Medicine in Sosnowiec, Medical University of \\ Silesia, Katowice, Poland; ${ }^{2}$ Department of General, Endocrine and Oncologic Surgery, Multidisciplinary Hospital, Jaworzno, Poland; and ${ }^{3}$ Section \\ of Gastrointestinal Motility, Multidisciplinary Hospital, Jaworzno, Poland
}

\section{Background/Aims}

The study aimed to determine pre- and post-fundoplication esophagogastric junction (EGJ) pressure and esophageal peristalsis by high-resolution manometry (HRM) in patients with gastroesophageal reflux disease (GERD).

\section{Methods}

Pre-operative and post-operative HRM data from 25 patients with GERD were analyzed using ManoView version 2.0.1. with updated software for Chicago classification and pressure topography. The study involved swallowing water boluses of $10 \mathrm{~mL}$ in the upright position.

\section{Results}

Significant increase of mean basal EGJ pressure and minimal basal EGJ pressure was found in post-operative as compared with preoperative patients $(P<0.05$ and $P<0.001$, respectively). Integrated relaxation pressure (IRP) reached higher values in post-operative patients than in pre-operative patients $(P<0.001)$. Intra-bolus pressure (IBP) was significantly higher $(P<0.05)$ and contractile front velocity (CFV) was slower $(P<0.01)$ in post-operative patients than in pre-operative patients. Moreover significant increase of distal contractile integral $(\mathrm{DCl})$ was found in post-operative patients $(P<0.05)$. Hiatal hernia was detected by HRM in 11 pre-operative patients. Fifteen out of 25 post-operative patients complained of dysphagia.

\section{Conclusions}

Fundoplication restores the antireflux barrier by reinforcing EGJ basal pressures, repairing hiatal hernias, and enhances peristaltic function of the esophagus by increasing DCl. However slight IRP elevation found in post-fundoplication patients may result in bolus pressurization and motility disorders.

(J Neurogastroenterol Motil 2017;23:55-63)

\section{Key Words}

Esophageal motility disorders; Fundoplication; Gastroesophageal reflux disease; Hiatal hernia; Manometry

Received: April 12, 2016 Revised: July 13, 2016 Accepted: July 24, 2016

(5) This is an Open Access article distributed under the terms of the Creative Commons Attribution Non-Commercial License (http://creativecommons. org/licenses/by-nc/4.0) which permits unrestricted non-commercial use, distribution, and reproduction in any medium, provided the original work is properly cited.

*Correspondence: Antoni Stadnicki, MD

Department of Basic Biomedical Sciences, Medical University of Silesia, 3, Kasztanowa Street, 41-205 Sosnowiec, Poland Tel: +48-32-2699830, Fax: +48-32-2945548, E-mail: astadnic@wp.p 


\section{Introduction}

Gastroesophageal reflux disease (GERD) is a chronic disorder that significantly deteriorates the quality of life. Treatment options include either long-term use of proton pump inhibitors (PPI) or antireflux surgery. Post-operative high-resolution manometry (HRM) examination may enable control of antireflux procedure effectiveness. ${ }^{1-4}$ We believe that the Chicago classification of esophageal motility would be useful to understand the post-fundoplication HRM patterns, because this surgical procedure is common and it is associated with a significant number of post-operative symptoms that might relate to esophageal motility. Most of the study results on this subject have been presented either as pre-operative or postoperative data which do not include paired analysis of individual changes of the Chicago classification parameters in the same patients before and after fundoplication. ${ }^{1-3}$ Scheffer et $\mathrm{al}^{5}$ found increased intra-bolus pressure (IBP) and increased esophagogastric junction (EGJ) relaxation pressure in patients after fundoplication. Recent studies conducted by Marjoux et $\mathrm{al}^{6}$ included pre- and post-operative analysis of Chicago classification parameters which showed mainly EGJ resting pressure improvement with frequent EGJ relaxation impairment leading to simultaneous motility disorders in post-fundoplication patients.

Effective esophageal motility determines esophageal clearance, which is of particular significance for patients with GERD qualified for antireflux surgery. The International HRM Working Group suggested using distal contractile integral (DCI) cutoff values to evaluate peristaltic contractions. According to the very recent update of the Chicago classification of esophageal motility disorders v 3.0, both failed ( $\geq 50 \%$ of swallows with DCI $<$ $100 \mathrm{mmHg} \cdot \mathrm{sec} \cdot \mathrm{cm})$ and weak ( $\geq 50 \%$ of swallows with DCI between $100-450 \mathrm{mmHg} \cdot \mathrm{sec} \cdot \mathrm{cm})$ peristaltic contractions are defined as ineffective esophageal motility (IEM), representing minor disorders of peristalsis with impaired esophageal clearance. ${ }^{7,8}$ Previously Goldani et $\mathrm{al}^{9}$ demonstrated, that DCI was significantly lower in pediatric patients with feeding difficulties, dysphagia or in those who were considered for fundoplication, than in children with no peristaltic dysfunction.

Fundoplication is the "gold standard" for GERD treatment as an alternative to pharmacological therapy in PPI non-responders, or when PPI long term therapy is not suitable. ${ }^{5,6,9}$ By re-establishing successful EGJ resting pressure and hiatal hernia repair, fundoplication eliminates mechanical factors responsible for reflux events, providing effective and long-term heartburn control in $90 \%$ of the patients. Fundoplication not only enhances the EGJ barrier but also alters esophageal motility. However, in spite of good reflux control results, up to $90 \%$ of post-fundoplication patients report dysphagia during the first 3 months after surgery, which resolves gradually within 5 years following the surgery. ${ }^{5,6,10,11}$ Clinical relevance of HRM findings in post-operative patients with complications still remains poorly understood. It was suggested that the disordered esophageal motor function can be an underlying cause of dysphagia and chest pain. ${ }^{8}$

This present study is one of the very first to report on the Chicago classification of esophageal motility disorders v 3.0 for the analysis of esophageal peristalsis, including percentage of IEM in patients with GERD before and after fundoplication. The primary objective of this study was to evaluate HRM profile of GERD patients before and after antireflux surgery to give insights into esophageal motor dysfunctions and their clinical implications.

\section{Materials and Methods}

\section{Patients}

Twenty-five consecutive patients of Caucasian ethnicity (15 women, 10 men; mean age $46.8 \pm 14.2$; range: $25-73$ years) with chronic GERD were included in this prospective research. All patients suffered from typical refractory symptoms of GERD, eg, heartburn and/or regurgitations despite PPI therapy. The patients were administered PPI once daily or periodically twice daily at least 6 months before participation in the study. Upper gastrointestinal (GI) endoscopy was performed in all patients before antireflux surgery. Eighteen patients had sliding hiatal hernia, 12 had reflux esophagitis (7 of those grade A, 4 of those grade B, and 1 grade 3 ) of Los Angeles Classification, and 6 had Barrett's esophagus. All of these patients underwent HRM examinations at the Section of Gastrointestinal Motility at Multidisciplinary Hospital in Jaworzno and were classified for laparoscopic Nissen fundoplication. HRM examinations were performed in each patient twice: before fundoplication and from 3 to 5 months after the surgery. Seven additional patients were excluded from the study due to difficulties in HRM catheter positioning, no consent to participate in a study and suspicious of malignancy. The information regarding symptoms (heartburn, epigastric pain, regurgitations, dysphagia, gas bloating syndrome, and non-cardiac chest pains) applied treatment, and medical test results taken from pre- and post-operative patients were gathered in a questionnaire. Patients were also informed to discontinue a minimum of 72 hours before HRM examination any prokinetic 
drugs, $\mathrm{H}_{2}$-blockers, PPIs, calcium channel blockers, nitrates, and anticholinergic drugs. The research was approved by the local Ethics Committee of the Medical University of Silesia (approval No. $\mathrm{KNW} / 0022 / \mathrm{KB} 1 / 105 / \mathrm{I} / 10$ ) on 12-OCT-2010. All subjects gave written informed consent and the study was performed according to the Declaration of Helsinki.

\section{High-resolution Manometry and Study Protocol}

All patients underwent high-resolution manometry (Sierra Scientific Instruments, Los Angeles, USA) using solid-state catheter with 36 circumferentially incorporated sensors spaced at $1-\mathrm{cm}$ intervals. The data were analyzed using ManoView $Z$ version 2.0.1. with updated software for Chicago classification and pressure topography.

To assess adequately the EGJ relaxation pressure, the integrated relaxation pressure (IRP) was computed within swallow-induced for 4 continuous or non-continuous seconds of the lowest mean pressures, while evaluation of antireflux barrier efficiency was done by measuring the resting EGJ pressures during the period without swallowing (minimal and mean basal EGJ pressure). Esophageal body function was evaluated by DCI (complex parameter integrating length of distal esophageal segment, contractile pressure and duration of contraction), IBP, contractile front velocity (CFV) and percentage of double-peaked waves. DCI was calculated at 20 $\mathrm{mmHg}$ isocontour in the rectangle area spanning from the proximal to distal pressure troughs or EGJ, encompassing esophageal smooth muscle peristaltic contraction.

The evidence of hiatal hernia in HRM was dual high-pressure zone (DHPZ) presence in the area of EGJ characterized by 2 high pressure bands corresponding respectively to the lower esophageal sphincter (LES) and the crural diaphragm contraction separated by distance.

Studies were done in the upright position in a fasting state. After trans-nasal catheter positioning, a 5-minute period of adaptation was required, and then the gastric and esophageal baseline pressures were recorded during 30 seconds without swallowing (Landmark). The manometric protocol included registration of 10 consecutive swallows of $10 \mathrm{~mL}$ of water administered by a syringe every $30 \mathrm{sec}-$ onds.

The normal values ranges for all esophageal motility parameters and EGJ pressures were established as a consensus between the manufacturer's recommendations and Chicago classification criteria.

\section{Statistical Methods}

The data gathered from 25 patients before and after fundoplication were expressed as median with interquartile ranges and minimum and maximum values. Variables from pre- and post-operative patients were compared using the Wilcoxon test for paired samples and also the McNemar's test was done to evaluate if the surgery had influenced the values normalizations. Also, the Mann-Whitney $\mathrm{U}$ test was performed to compare HRM data in post-operative patients with and without dysphagia. $P$-values $<0.05$ was considered significant for all statistical tests. Also, Spearman's rank correlation analysis was done to determine correlations between DCI and mean basal EGJ pressures or between DCI and minimal basal EGJ pressures in post-fundoplication patients.

\section{Results}

\section{Patients}

The most common symptoms reported by patients with GERD before and after fundoplication are gathered in Table 1. Control follow-up examination was performed in all patients 3-5 months after antireflux surgery.

Statistically significant improvement of GERD symptoms (heartburn, epigastric pain) was noted in most patients after the surgical procedure. None of the patients complained of dysphagia before antireflux surgery, however 15 out of 25 patients reported its presence after fundoplication. Post-operative dysphagia was graded in four-point Likert- like scale. Nine patients complained of mild, five of moderate, and one of severe dysphagia. Post-operative HRM data of 15 patients with dysphagia were compared with those of 10 patients without dysphagia and gathered in Table 2 .

Table 1. Clinical Symptoms in Pre- and Post-operative Patients

\begin{tabular}{lcc}
\hline \multicolumn{1}{c}{ Symptoms } & $\begin{array}{c}\text { Pre-operative } \\
\text { patients } \\
(\mathrm{n}=25)\end{array}$ & $\begin{array}{c}\text { Post-operative } \\
\text { patients } \\
(\mathrm{n}=25)\end{array}$ \\
\hline Heartburn & 23 & $2^{\mathrm{a}}$ \\
Epigastric pain & 15 & $4^{\mathrm{a}}$ \\
NCCP & 4 & 2 \\
Nausea/vomiting & 8 & 6 \\
Regurgitations & 4 & - \\
Dysphagia & - & $15^{\mathrm{a}}$ \\
Gas bloating syndrome & - & 5 \\
\hline${ }^{\mathrm{a}} P<0.01 ;$ McNemar's test. & & \\
NCCP, non-cardiac chest pains. & &
\end{tabular}


Table 2. Comparison of High-resolution Manometry Data in Post-operative Patients with and Without Dysphagia

\begin{tabular}{|c|c|c|c|}
\hline & $\begin{array}{l}\text { Post-operative patients with dysphagia } \\
\qquad(\mathrm{n}=15) \\
\text { median }(\mathrm{IQR}) \\
{[\text { minimum-maximum }]}\end{array}$ & $\begin{array}{l}\text { Post-operative patients without dysphagia } \\
\qquad(\mathrm{n}=10) \\
\text { median }(\mathrm{IQR}) \\
{[\text { minimum-maximum }]}\end{array}$ & $P$-value ${ }^{a}$ \\
\hline $\operatorname{IRP}(\mathrm{mmHg})$ & $\begin{array}{c}6.0(3.4-12.1) \\
{[1.8-38.9]}\end{array}$ & $\begin{array}{c}5.5(1.2-11.0) \\
{[0.1-12.3]}\end{array}$ & 0.192 \\
\hline $\mathrm{IBP}(\mathrm{mmHg})$ & $\begin{array}{c}13.6(11.7-24.6) \\
{[3.7-49.9]}\end{array}$ & $\begin{array}{c}14.4(12.5-20.8) \\
{[4.2-27.9]}\end{array}$ & 0.890 \\
\hline $\mathrm{DCI}(\mathrm{mmHg} \cdot \mathrm{sec} \cdot \mathrm{cm})$ & $\begin{array}{c}1452.3 \\
(877.7-2321.5) \\
{[278.0-4439.0]}\end{array}$ & $\begin{array}{c}821.3 \\
(658.6-1008.6) \\
{[528.6-3395.0]}\end{array}$ & 0.142 \\
\hline $\mathrm{CFV}(\mathrm{cm} / \mathrm{sec})$ & $\begin{array}{c}3.0(1.9-4.5) \\
{[1.3-105.3]}\end{array}$ & $\begin{array}{c}2.9(2.7-4.0) \\
{[-12.6-4.8]}\end{array}$ & 0.760 \\
\hline Double-peaked waves (\%) & $\begin{array}{c}10.0(0.0-27.0) \\
{[0.0-78.0]}\end{array}$ & $\begin{array}{c}10.0(0.0-20.0) \\
{[0.0-45.0]}\end{array}$ & 0.798 \\
\hline
\end{tabular}

${ }^{a}$ The Mann-Whitney U test.

IRQ, interquartile range; IRP, integrated relaxation pressure; IBP, intra-bolus pressure; DCI, distal contractile integral; CFV, contractile front velocity.

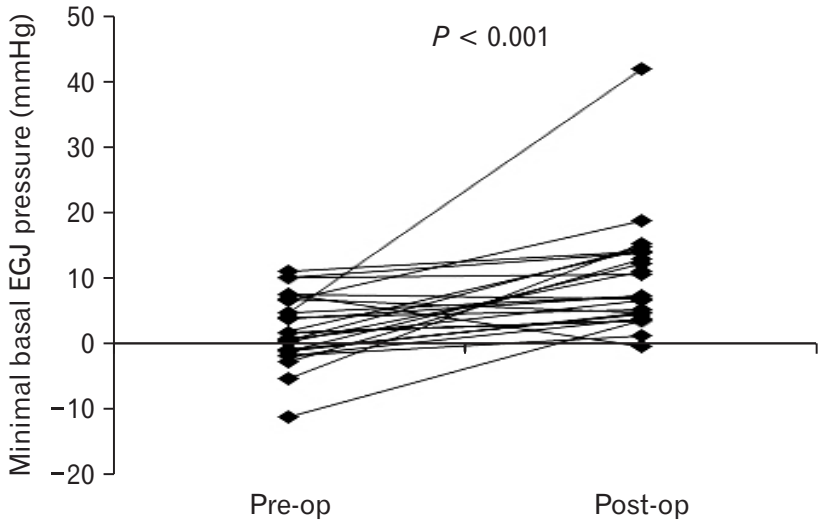

Figure 1. Individual changes of minimal basal esophagogastric junction (EGJ) pressure in pre-operative (pre-op) and post-operative patients (post-op): in 22 patients increase while in 3 patients decrease of minimal basal EGJ pressure were shown after fundoplication (normal values range: $4.8-32.0 \mathrm{mmHg}$ ).

No statistical significance was found and no post-operative manometric parameters were related to post-operative dysphagia. After fundoplication upper GI endoscopy was performed in all patients. Neither esophagitis nor hiatal hernia was observed in post-operative patients. Later on, one patient with severe dysphagia (associated with elevated IRP in HRM) was qualified for endoscopic dilatation.

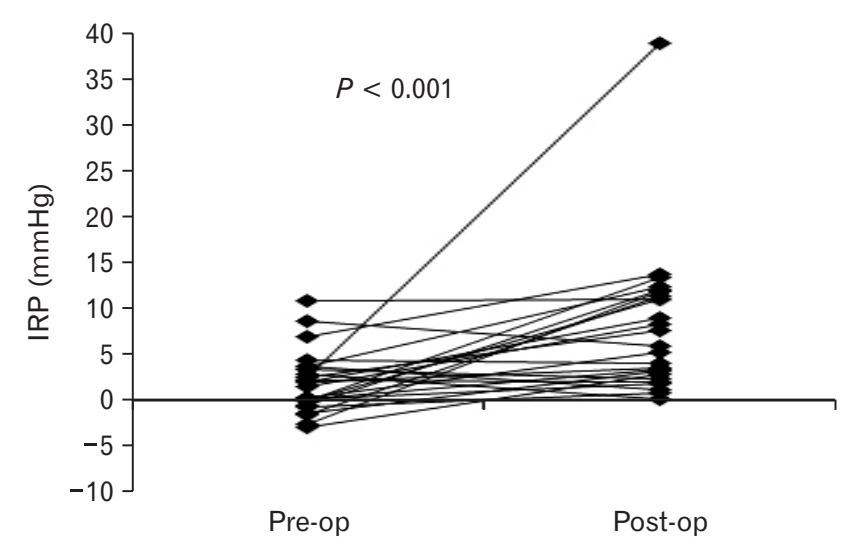

Figure 2. Individual changes of integrated relaxation pressure (IRP) in pre-operative (pre-op) and post-operative patients (post-op): in 19 patients increase while in 6 patients decrease of integrated relaxation pressure were shown after fundoplication (normal values range: $<15$ $\mathrm{mmHg})$.

\section{Esophagogastric Junction Pressure Profile and Esophageal Pressure Topography Analysis}

\section{Esophagogastric junction}

In post-operative patients mean basal EGJ pressure was significantly higher than in pre-operative patients $(P<0.05$; Wilcoxon test). Moreover, a trend to normalization (normal values range: $10-$ $35 \mathrm{mmHg}$ ) of this parameter was observed after fundoplication $(P$ $=0.070$, McNemar's test).

Minimal basal EGJ pressure was also significantly higher in 
post-operative patients as compared with pre-operative $(P<0.001$, Wilcoxon test, Fig. 1). Moreover, referring to normal values range, fundoplication caused normalization of this parameter $(P<0.05$, McNemar's test).

LES relaxation pressure expressed as IRP was significantly higher in post-operative than in pre-operative patients $(P<0.001$, Wilcoxon test, Fig. 2). This parameter was always within normal values range in patients before fundoplication while after the surgery it was elevated in one patient. However, McNemar's test did not show that fundoplication significantly impaired the LES relaxation.

Abnormal high values of minimal EGJ pressure $(41.9 \mathrm{mmHg})$ and IRP (38.9 mmHg), seen in Figures 1 and 2, refer to one patient who was further qualified for endoscopic dilatation.

Intraoperative diagnosis confirmed the presence of hiatal hernia in 23 patients but after fundoplication no hiatal hernia was detected by HRM. The presence of a sliding hiatal hernia was confirmed in 11 out of 25 patients by HRM before the surgery.

\section{Esophageal motility}

Distal contractile integral (DCI) was significantly higher in post-operative as compared with pre-operative patients $(P<0.05$,
Wilcoxon test, Fig. 3), however based on the DCI threshold (450 $\mathrm{mmHg} \cdot \mathrm{sec} \cdot \mathrm{cm})$, only a trend from ineffective to effective esophageal motility was observed ( $P=0.070, \mathrm{McNemar}$ 's test). According to the most recent update of the Chicago classification, ${ }^{7}$ ineffective esophageal motility with minor disorders of peristalsis (impaired

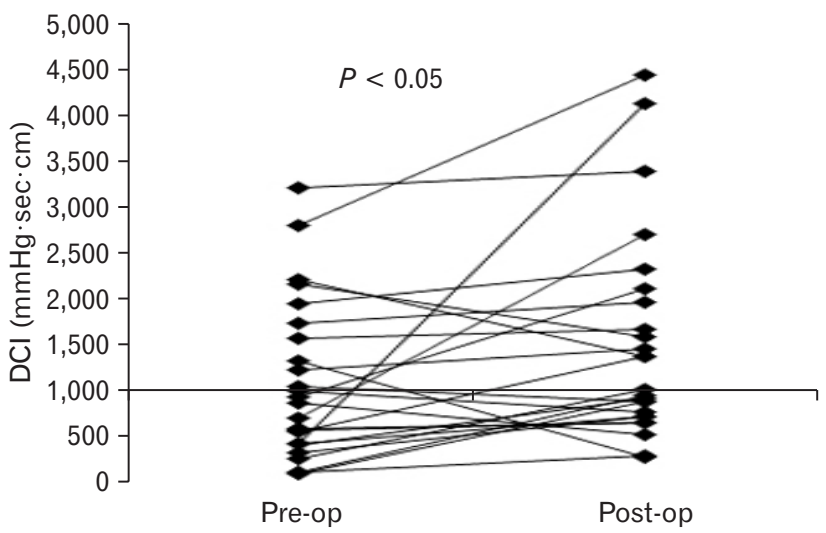

Figure 3. Individual changes of distal contractile integral (DCI) in pre-operative (pre-op) and post-operative patients (post-op): in 19 patients increase while in 6 patients decrease of distal contractile integral were shown after fundoplication (normal values range: 500-4300 $\mathrm{mmHg} \cdot \mathrm{sec} \cdot \mathrm{cm})$.

Table 3. Esophagogastric Junction Profile Pressures and Esophageal Motility by High-resolution Manometry in Pre- and Post-operative Patients.

\begin{tabular}{|c|c|c|c|c|}
\hline & $\begin{array}{c}\text { Normal } \\
\text { values } \\
\text { range }\end{array}$ & $\begin{array}{l}\text { Pre-operative patients } \\
\qquad(\mathrm{n}=25) \\
\text { median (IQR) } \\
\text { [minimum-maximum] }\end{array}$ & $\begin{array}{l}\text { Post-operative patients } \\
\qquad(\mathrm{n}=25) \\
\text { median }(\mathrm{IQR}) \\
\text { [minimum-maximum] }\end{array}$ & $P$-value \\
\hline Mean basal EGJ pressure $(\mathrm{mmHg})$ & $10-35$ & $\begin{array}{c}10.0(5.7-15.6) \\
{[-4.8-39.9]}\end{array}$ & $\begin{array}{c}15.8(10.2-23.7) \\
{[5.2-57.0]}\end{array}$ & $<0.05$ \\
\hline Minimal basal EGJ pressure ( $\mathrm{mmHg}$ ) & $4.8-32.0$ & $\begin{array}{l}1.8(-1.1-6.5) \\
{[-11.2-11.0]}\end{array}$ & $\begin{array}{c}7.3(4.6-13.9) \\
{[-0.3-42.0]}\end{array}$ & $<0.001$ \\
\hline $\operatorname{IRP}(\mathrm{mmHg})$ & $<15$ & $\begin{array}{l}2.0(0.0-3.3) \\
{[-2.9-10.9]}\end{array}$ & $\begin{array}{c}6(2.9-11.4) \\
{[0.1-38.9]}\end{array}$ & $<0.001$ \\
\hline $\mathrm{IBP}(\mathrm{mmHg})$ & $<15$ & $\begin{array}{c}10.0(6.2-14.1) \\
{[0.3-33.3]}\end{array}$ & $\begin{array}{c}13.9(11.7-20.8) \\
{[3.7-49.9]}\end{array}$ & $<0.05$ \\
\hline $\mathrm{DCI}(\mathrm{mmHg} \cdot \mathrm{sec} \cdot \mathrm{cm})$ & $500-4300$ & $\begin{array}{c}859.0(430.0-1574.0) \\
{[94.0-3204.0]}\end{array}$ & $\begin{array}{c}1008.0(725.0-1968.0) \\
{[278.0-4439.0]}\end{array}$ & $<0.05$ \\
\hline $\mathrm{CFV}(\mathrm{cm} / \mathrm{sec})$ & $2.6-5.3$ & $\begin{array}{c}4.3(3.1-5.4) \\
{[2.4-16.5]}\end{array}$ & $\begin{array}{c}2.9(2.0-4.0) \\
{[1.1-7.5]}\end{array}$ & $<0.01$ \\
\hline Double-peaked waves (\%) & $\leq 15$ & $\begin{array}{c}0.0(0.0-0.0) \\
{[0.0-22.0]}\end{array}$ & $\begin{array}{c}10.0(0.0-20.0) \\
{[0.0-78.0]}\end{array}$ & $<0.01$ \\
\hline Mean wave duration (sec) & $2.7-5.4$ & $\begin{array}{c}3.1(2.6-3.9) \\
{[2.2-5.3]}\end{array}$ & $\begin{array}{c}3.5(3.2-4.7) \\
{[2.3-8.0]}\end{array}$ & $<0.01$ \\
\hline Hiatal hernia by HRM & & $11(44 \%)$ & $0(0 \%)$ & \\
\hline
\end{tabular}

${ }^{a}$ Wilcoxon test.

IRQ, interquartile range; EGJ, esophagogastric junction; IRP, integrated relaxation pressure; IBP, intra-bolus pressure; DCI, distal contractile integral; CFV, contractile front velocity; HRM, high-resolution manometry. 
clearance) was present in $11(44 \%)$ pre-operative patients as follows: 2 (8\%) patients had $\geq 50 \%$ of swallows with failed peristalsis (DCI $<100 \mathrm{mmHg} \cdot \mathrm{sec} \cdot \mathrm{cm}), 3(12 \%)$ patients had $\geq 50 \%$ of swallows with weak peristalsis (DCI 100-450 $\mathrm{mmHg} \cdot \mathrm{sec} \cdot \mathrm{cm}$ ), and $6(24 \%)$ patients presented $\geq 50 \%$ of swallows with both weak and failed peristalsis. Before fundoplication 14 (56\%) patients had normal esophageal peristalsis (IRP normal and $>50 \%$ effective swallows with DCI $>450 \mathrm{mmHg} \cdot \mathrm{sec} \cdot \mathrm{cm}$ but $<8000 \mathrm{mmHg} \cdot \mathrm{sec} \cdot \mathrm{cm}$ ). After fundoplication ineffective esophageal motility was present in $6(24 \%)$ patients as follows: $1(4 \%)$ patient had $\geq 50 \%$ of swallows with failed peristalsis, $3(12 \%)$ had $\geq 50 \%$ of swallows with weak peristalsis and $2(8 \%)$ patients presented $\geq 50 \%$ of swallows with both weak and failed peristalsis. Eighteen (72\%) post-operative patients met the criteria of normal peristalsis. One post-operative patient had EGJ outflow obstruction (IRP $\geq$ upper normal limit and not type I-III achalasia). EGJ and esophageal motility parameters are presented in Table 3.

Slightly increased DCI value $(4439 \mathrm{mmHg} \cdot \mathrm{sec} \cdot \mathrm{cm})$ seen in Figure 3 pertains to one post-operative patient with normal: mean EGJ pressure, minimal EGJ pressure, IRP, and IBP values.

In patients after fundoplication the intra-bolus pressure (IBP) was also significantly higher than in patients with GERD before fundoplication $(P<0.05$, Wilcoxon test; Fig. 4). Nevertheless, the McNemar's test did not show that antireflux surgery might significantly deteriorate bolus transport and abnormal IBP values. IBP was elevated ( $>15 \mathrm{mmHg}$ ) in 6 pre-operative patients (all with hiatal hernia confirmed by HRM) and in 10 post-operative patients.

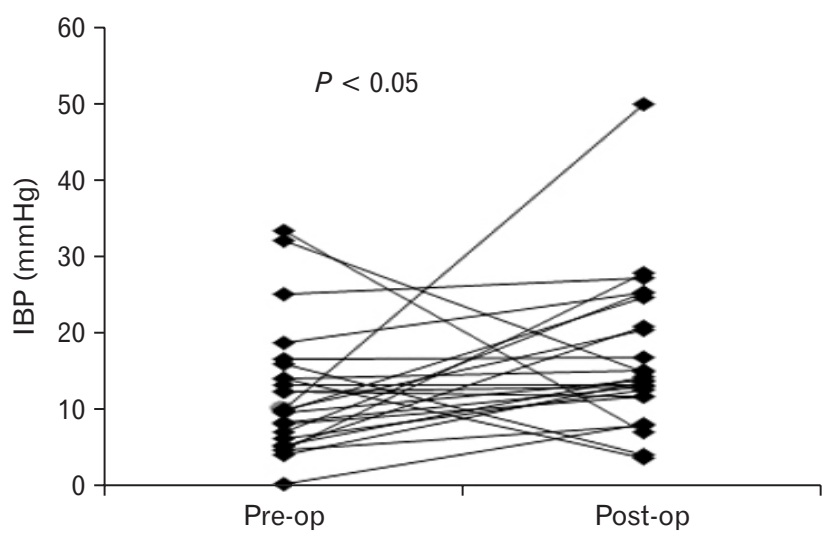

Figure 4. Individual changes of intra-bolus pressure (IBP) in preoperative (pre-op) and post-operative patients (post-op): in 19 postoperative patients increase while in 5 patients decrease of intra-bolus pressure were shown, in one patient IBP wasn't altered after fundoplication (normal values range: $<15 \mathrm{mmHg}$ ).
Contractile front velocity (CFV) was significantly lower in post-operative than in pre-operative patients $(P<0.01$, Wilcoxon test). However, referring to normal values ranges, the antireflux procedure did not statistically influence the normalization of this parameter which was assessed by the McNemar's test. CFV results in 14 pre- and 13 post-operative patients were within normal values ranges $(2.6-5.3 \mathrm{~cm} / \mathrm{sec})$.

One post-operative patient with abnormal high IBP (49.9 $\mathrm{mmHg}$ ) seen in Figure 4 had -increased percentage of double peaked waves (78\%) with normal EGJ relaxation and resting pressure profile.

Double-peaked waves were more frequent in post-operative as compared with pre-operative patients ( $P<0.01$, Wilcoxon test). Moreover, it was shown that fundoplication significantly induced the percentage of double-peaked waves $(P<0.05$, McNemar's test). This parameter was elevated $(>15 \%)$ in 3 patients before surgery and in 10 patients after fundoplication.

\section{Distal contractile integral and mean basal esophago- gastric junction pressure or distal contractile integral and minimal basal esophagogastric junction pressure in post-operative patients}

Only a trend for correlation between the DCI and mean basal EGJ pressure was observed (Spearman's rank correlation; $P$-value $=0.066$ and correlation coefficient $r=0.37$ ).

No correlation was found between the DCI and minimal basal EGJ pressure in post-fundoplication patients.

\section{Discussion}

In our study we have managed to show that Nissen fundoplication restored resting EGJ pressures (minimal and mean basal EGJ pressures) together with a trend to normalization or significant normalization of the EGJ pressure profile, respectively (in GERD patients before fundoplication the minimal basal EGJ pressure was more frequently below the normal values ranges than the mean basal EGJ pressure). Thus the heartburn symptoms present in preoperative patients with GERD enrolled in our study, were eliminated in 21 of 23 patients after fundoplication. Similarly, Marjoux et $\mathrm{al}^{6}$ described increased EGJ resting pressures in patients after fundoplication and successful GERD symptoms relief. Also, Tatum et $\mathrm{al}^{2}$ showed that the effectiveness of fundoplication procedure is related to higher mean LES resting pressure. Moreover, the presence of DHPZ in post-fundoplication patients corresponds with intrathoracic or slipped fundoplication, predicting fundoplication failure 
and GERD symptoms recurrence. ${ }^{2,3}$ However in post-operative patients examined by HRM in our study, no DHPZ was found.

Integrated relaxation pressure as the most adequate parameter describing EGJ relaxation was within the normal values ranges in all GERD patients examined in our study before fundoplication (hiatal hernia was detected by HRM in 11). Consequently, normal IRP values in all our patients with GERD corresponded with proper swallow-induced EGJ relaxation. In post-operative patients IRP was significantly higher than in pre-operative patients, however, IRP was elevated only in one patient after surgery indicating a mechanical obstruction (patient qualified for endoscopic dilatation). Exceeding the IRP cutoff value of $15 \mathrm{mmHg}$ in postfundoplication patients reflects consequences of the antireflux barrier reinforcement with EGJ outflow obstruction. Increased EGJ relaxation pressure, expressed often less precisely by the residual EGJ relaxation pressure, was previously described by many authors in patients after fundoplication. ${ }^{3,5,6}$ Undoubtedly, IRP is more comprehensive in evaluating EGJ relaxation as it integrates measurements of all the components affecting bolus transport across EGJ, LES, crural opening, and IBP. ${ }^{12}$ Fundoplication may reduce hiatal opening leading to restricted deglutitive EGJ relaxation, and as a consequence to considerable IRP values alternations. ${ }^{5}$ In this study together with IRP increase and also IBP increase was shown in post-fundoplication patients, indicating possible functional outflow obstruction either at the EGJ level or along the esophagus. Moreover, in 4 out of 6 pre-operative patients with elevated IBP values, hiatal hernia was also present, while in the remaining 2 patients besides hiatal hernia spastic disorders were found ( $\mathrm{CFV}>8 \mathrm{~cm} / \mathrm{sec}$ ). In post-operative patients increased IBP (10/25) corresponded with impaired LES relaxation (1/10), and abnormal percentage of double-peaked waves (3/10). In 6 out of 10 post-operative patients with elevated IBP no accompanying serious alternations in motility parameters were found. Increased IBP in patients after fundoplication have been commonly described by other authors. ${ }^{5,13}$ The presence of fundoplication wrap can be a region forming resistance to flow which enhances the forces to drive the bolus passage (higher DCI $)^{6,14}$

In this study, significant DCI rise in post-fundoplication patients was also shown as compared with pre-operative patients, together with a trend from ineffective to effective esophageal motility (applying the cutoff value for DCI of $450 \mathrm{mmHg} \cdot \mathrm{sec} \cdot \mathrm{cm}$ as the optimal threshold to predict ineffective esophageal motility). In our study 11 (44\%) pre-operative patients had IEM ( $\geq 50 \%$ of swallows with weak and failed peristalsis) and 6 (24\%) after the surgery. IEM is a minor motility disorder characterized by impaired esoph- ageal bolus transit. ${ }^{7}$ Neither achalasia nor major disorders of peristalsis was observed in our pre- and post-operative patients. IEM was previously reported by other researchers as the most prevalent esophageal motor disorder in GERD, found in 21-38\% of patients in a large series, and its presence was associated with the severity of acid exposure and reflux symptoms. ${ }^{15}$ Minor motility disorders that meet the criteria for IEM are probably the least studied manifestations of esophageal dysfunctions due to apparent lack of therapeutic options. There is no pharmacological treatment that reliably restores smooth muscle contractility and esophageal function. ${ }^{15}$

Laparoscopic Nissen fundoplication is the most common surgery performed for GERD. The results of the studies on tailoring the degree of the operation (eg, complete Nissen wrap versus posterior Toupet wrap) to the esophageal motility pattern have inconclusive results. Thus the relation between pre-operative IEM and surgery outcome should be interpreted with caution. ${ }^{15}$ Many patients with pre-operative minor disorders of peristalsis (impaired clearance) may actually benefit from Nissen fundoplication since the esophageal motility improves post-operatively, as it was demonstrated in this study. We believe that tailoring the operation to the degree of IEM is often not required to achieve a successful symptomatic and functional post-operative outcome.

Improvement of distal esophageal segment contraction is of special significance for GERD patients, and it is probably due to adaptive mechanisms induced by post-fundoplication rise of the mean basal EGJ pressure. DCI cutoff values were previously established in determining rare primary hypertensive peristaltic disorders such as the "nutcracker esophagus" or hypercontractile disorders such as the "jackhammer esophagus." "16 The International HRM Working Group recently clarified that at the other extreme of DCI values scale, abnormal high DCI values between 5000 and 8000 $\mathrm{mmHg} \cdot \mathrm{sec} \cdot \mathrm{cm}$ have no apparent clinical significance, ${ }^{7,8,17} \mathrm{DCI} \geq$ $8000 \mathrm{mmHg} \cdot \mathrm{sec} \cdot \mathrm{cm}$ is thought to be clinically relevant since it is associated with chest pain and dysphagia indicating hypercontractility. ${ }^{7,17}$ None of pre- and post-operative patients in this study demonstrated DCI values exceeding $8000 \mathrm{mmHg} \cdot \mathrm{sec} \cdot \mathrm{cm}$.

Furthermore, in patients after fundoplication examined in this study the frequency of double-peaked waves was significantly increased as compared with patients before surgery. Clouse et $\mathrm{al}^{18}$ previously suggested that double-peaked waves may be associated with inadequate inhibitory nerve function of the distal esophagus. Abnormally high frequency of multipeaked waves often goes together with increased distal waves amplitude, prolonged wave duration characteristic for diffuse esophageal spasm or "nutcracker esophagus. ${ }^{\$ 8,19}$ Double-peaked waves can also be found in diabetic pa- 
tients with autonomic neuropathy. ${ }^{20}$ In our study, it was shown that fundoplication induced increased the frequency of double-peaked waves ( $40 \%$ of post-operative patients vs $12 \%$ of pre-operative patients with elevated double-peaked waves). According to Sampath et $\mathrm{al}^{21}$ double-peaked waves are the result of respiratory-related movement of the distal esophageal segment which moves with inspiration and expiration in respect to stable pressure sensors of the HRM catheter. In the presence of prolonged contraction duration or slower velocity of peristalsis (both constituting fundamental abnormality of multipeaked waves), several respiratory phase reversals may occur, generating more double-peaked waves. ${ }^{21}$ This hypothesis is quite convincing because in post-operative patients examined in our study, prolonged contraction duration as well as slower contractile front velocity were found. Moreover, it was also suggested that increased frequency of double-peaked waves may be manifested by the most common post-fundoplication symptom-dysphagia. ${ }^{18}$ In our research $60 \%$ of patients complained of dysphagia after the surgery but none before fundoplication. Previously, Marjoux et $\mathrm{al}^{6}$ established that post-operative dysphagia was associated with higher values of IRP. However, we did not find any statistical significance comparing HRM profile between post-operative patients with and without dysphagia. Moreover, other studies demonstrated that preoperative esophageal manometry is not sufficient to accurately predict post-operative dysphagia. ${ }^{6}$

Our results are in line with studies done by other researchers showing that dysphagia can affect up to $90 \%$ of post-fundoplication patients. ${ }^{5,10,11,22}$ In patients after antireflux procedure there can be other factors contributing to dysphagia, such as individual lower sensory threshold during bolus distension, surgery-related factors like degree, tightness, and length of fundoplication wrap. ${ }^{5,9,11}$ The most precise measuring methods of HRM still do not result in better understanding of correlation between motility, bolus transport and symptoms like dysphagia. ${ }^{8}$ Even in patients with complete absence of peristalsis -symptoms may be absent. On the other hand, one can find patients who complain of severe dysphagia but who have completely normal esophageal peristalsis and EGJ function. ${ }^{15}$

The impact of fundoplication on esophageal motility and EGJ pressures and its clinical implications is very a sophisticated matter. In our study post-operative evaluation was performed relatively early after antireflux surgery, which may explain the high number of our patients who complained of dysphagia. This corresponds to other studies which reported dysphagia in up to $70 \%$ of patients six months after surgery. ${ }^{23,24}$

Undoubtedly, the small number of recruited patients is the limitation of our study. Thus further research on a more representa- tive population should be continued to establish clear HRM values corresponding to successfully performed procedures, effectively controlling refluxes, or values indicating the need of re-operation. Another limitation of this study is the lack of pre-operative $\mathrm{pH}$ esophageal monitoring to confirm pathological esophageal acid exposure.

In conclusion, HRM is a valuable tool for EGJ characteristics in GERD patients before and after fundoplication. Fundoplication restores the antireflux barrier by increasing EGJ resting pressures, repairing hiatal hernias, and enhances peristaltic function of the esophagus by increasing DCI. However, even a moderate increase of IRP may contribute to motility disorders and bolus pressurization in some patients after fundoplication. Our prospective study is one of the first to provide a comprehensive evaluation of esophageal and EGJ parameters of HRM in the same patients before and after fundoplication. The results of this study illustrate that pre- and post-operative HRM assessment of esophageal motility and EGJ pressure profiles should be the aim of further prospective research to expand our knowledge about surgical GERD treatment effectiveness.

Acknowledgements: We would like to thank Professor Stephen Attwood for his valuable input to this manuscript.

\section{Financial support: None.}

\section{Conflicts of interest: None.}

Author contributions: Katarzyna Rerych: designed the research study, analyzed the data, and wrote the paper; Józef Kurek: performed the study and provided essential equipment; Ewa Klimacka-Nawrot: analyzed the data and contributed to the writing of the paper; Barbara Błońska-Fajfrowska: contributed essential support and revised the paper critically; and Antoni Stadnicki: designed the research study, performed the research and analyzed the data and reviewed the manuscript including final approval of the version to be published.

\section{References}

1. Chan WW, Haroian LR, Gyawali CP. Value of preoperative esophageal function studies before laparoscopic antireflux surgery. Surg Endosc 2011;25:2943-2949.

2. Tatum RP, Soares RV, Figueredo E, Oelschlager BK, Pellegrini CA. High-resolution manometry in evaluation of factors responsible for fundoplication failure. J Am Coll Surg 2010;210:611-617. 
3. Hoshino M, Srinivasan A, Mittal SK. High-resolution manometry patterns of lower esophageal sphincter complex in symptomatic postfundoplication patients. J Gastrointest Surg 2012;16:705-714.

4. Bredenoord AJ, Fox M, Kahrilas PJ, Pandolfino JE, Schwizer W, Smout AJ. Chicago classification criteria of esophageal motility disorders defined in high resolution esophageal pressure topography. Neurogastroenterol Motil 2012;24(suppl 1):57-65.

5. Scheffer RC, Samsom M, Haverkamp A, Oors J, Hebbard GS, Gooszen HG. Impaired bolus transit across the esophagogastric junction in postfundoplication dysphagia. Am J Gastroenterol 2005;100:1677-1684.

6. Marjoux S, Roman S, Juget-Pietu F, et al. Impaired postoperative EGJ relaxation as determinant of post laparoscopic fundoplication dysphagia: a study with high-resolution manometry before and after surgery. Surg Endosc 2012;26:3642-3649.

7. Kahrilas PJ, Bredenoord AJ, Fox M, et al. The Chicago classification of esophageal motility disorders v3.0. Neurogastroenterol Motil 2015;27:160-174.

8. van Hoeij FB, Bredenoord AJ. Clinical application of esophageal highresolution manometry in the diagnosis of esophageal motility disorders. J Neurogastroenterol Motil 2016;22:6-13.

9. Goldani HA, Staiano A, Borrelli O, Thapar N, Lindley KJ. Pediatric esophageal high-resolution manometry: utility of a standardized protocol and size-adjusted pressure topography parameters. Am J Gastroenterol 2010;105:460-467.

10. Galmiche JP, Hatlebakk J, Attwood S, et al. Laparoscopic antireflux surgery vs esomeprazole treatment for chronic GERD: The LOTUS randomized clinical trial. JAMA 2011;305:1969-1977.

11. Tsuboi K, Lee TH, Legner A, Yano F, Dworak T, Mittal SK. Identification of risk factors for postoperative dysphagia after primary anti-reflux surgery. Surg Endosc 2011;25:923-929.

12. Dustin AC, Pandolfino JE. The Chicago criteria for esophageal motility disorders: what has changed in the past 5 years? Curr Opin Gastroeneterol 2012;28:395-402.
13. Ghosh SK, Pandolfino JE, Rice J, Clarke JO, Kwiatek M, Kahrilas PJ. Impaired deglutitive EGJ relaxation in clinical esophageal manometry: a quantitative analysis of 400 patients and 75 controls. Am J Physiol Gastrointest Liver Phsyiol 2007;293:G878-G885.

14. Fox MR, Bredenoord AJ. Oesophageal high-resolution manometry: moving from research into clinical practice. Gut 2008;57:405-423.

15. Smout A, Fox M. Weak and absent peristalsis. Neurogastroeneterol Motil 2012;24(suppl 1):40-47.

16. Roman S, Tutuian R. Esophageal hypertensive peristaltic disorders. Neurogastroenterol Motil 2012;24(suppl 1):32-39.

17. Xiao Y, Kahrilas PJ, Kwasny MJ, et al. High-resolution manometry correlates of ineffective esophageal motility. Am J Gastroenetrol 2012;107:1647-1654.

18. Clouse RE, Staiano A, Alrakawi A. Topographic analysis of esophageal double-peaked waves. Gastroenterology 2000;118:469-476.

19. Richter JE, Wu WC, Johns DN, et al. Esophageal manometry in 95 healthy adult volunteers. Variability of pressures with age and frequency of “abnormal" contractions. Dig Dis Sci 1987;32:583-592.

20. Loo FD, Dodds WJ, Soergel KH, Arndorfer RC, Helm JF, Hogan WJ. Multipeaked esophageal peristaltic pressure waves in patients with diabetic neuropathy. Gastroenterology 1985;88:485-491.

21. Sampath NJ, Bhargava V, Mittal RK. Genesis of multipeaked waves of the esophagus: repetitive contractions or motion artifact? Am J Physiol Gastrointest Liver Physiol 2010;298:G927-G933.

22. Broeders JA, Sportel IG, Jamieson GG, et al. Impact of ineffective oesophageal motility and wrap type on dysphagia after laparoscopic fundoplication. Br J Surg 2011;98:1414-1421.

23. Venkataraman J, Krishnan A. Long-term medical management of gastroesophageal reflux disease: how long and when to consider surgery? Trop Gastroenterol 2012;33:21-32.

24. Myers JC, Jamieson GG, Sullivan T, Dent J. Dysphagia and gastroesophageal junction resistance to flow following partial and total fundoplication. J Gastrointest Surg 2012;16:475-485. 